\title{
Nuclear field shift effect in isotope fractionation of thallium
}

\author{
Toshiyuki Fujii ${ }^{1,{ }^{*}}$, Frédéric Moynier ${ }^{2}$, Arnaud Agranier $^{3}$, Emmanuel Ponzevera $^{4}$, Minori Abe ${ }^{5}$ \\ Akihiro Uehara ${ }^{1}$, Hajimu Yamana ${ }^{1}$,
}

\footnotetext{
${ }^{1}$ Research Reactor Institute, Kyoto University, 2-1010 Asashiro Nishi, Kumatori, Sennan, Osaka, 590-0494, Japan

2 Department of Earth and Planetary Sciences and McDonnell Center for Space Sciences, Washington University in St. Louis, Campus Box 1169, 1 Brookings Drive, Saint Louis, MO, 63130-4862, USA

${ }^{3}$ UMR 6538, Domaines Océaniques, Institut Universitaire Européen de la Mer (IUEM), Place Nicolas Copernic, 29820, Plouzané, France

${ }^{4}$ Laboratoire de Géochimie et Métallogénie, Département Géosciences Marines, IFREMER, Z.I. Pointe du diable, BP 70, 29280, Plouzané, France

${ }^{5}$ Department of Chemistry, Graduate School of Science and Engineering, Tokyo Metropolitan University, 1-1 Minami-Osawa, Hachioji-shi, Tokyo, 192-0397, Japan
}

*: Corresponding author : Toshiyuki Fujii, email address : tosiyuki@rri.kyoto-u.ac.jp

\begin{abstract}
:
Environmental transport of $\mathrm{Tl}$ is affected by redox reaction between $\mathrm{TI}(\mathrm{I})$ and $\mathrm{TI}(\mathrm{III})$ and ligand exchange reactions of them. In order to deepen the knowledge of $\mathrm{Tl}$ chemistry, we investigated fractionation of $\mathrm{TI}$ stable isotopes $\left({ }^{203} \mathrm{TI}\right.$ and $\left.{ }^{205} \mathrm{TI}\right)$ in a chemical exchange system. $\mathrm{TI}$ isotopes were fractionated in a liquid-liquid extraction system, in which aqueous and organic phases are hydrochloric acid solution and dichloroethane including a crown ether, respectively. After purification by ionexchange chemistry, the isotope ratio of ${ }^{205} \mathrm{TI} /{ }^{203} \mathrm{TI}$ in equilibrated aqueous phase was measured precisely by multiple-collector-inductively-coupled-plasma-mass-spectrometry. A large isotope fractionation $>1 \%$ was found. Electronic structures of possible $\mathrm{TI}$ species (hydrated $\mathrm{Tl}^{+}, \mathrm{Tl}^{3+}$, and $\mathrm{TI}$ chlorides) were calculated by ab initio methods, and the isotope fractionation factor was theoretically obtained. The isotope fractionation via intramolecular vibrations was calculated to be much smaller than the experimental result. The isotope fractionation via isotopic change in nuclear volume, named the nuclear field shift effect, was calculated to be $>1 \%$ in $\mathrm{TI}(\mathrm{I})-\mathrm{TI}(\mathrm{III})$ redox systems and/or ligand exchange systems of $\mathrm{TI}(\mathrm{III})$. The nuclear field shift effect was found to be the major origin of $\mathrm{TI}$ isotope fractionation.
\end{abstract}

Keywords: Thallium ; Isotope fractionation ; Redox ; Ligand exchange ; Nuclear field shift ; Ab initio calculation 
Thallium is a highly toxic heavy element. Pollution by $\mathrm{Tl}$ is found in mining districts and its migration introduces Tl into surface water, soils, plants, and so on [1]. Environmental transport of $\mathrm{Tl}$ is affected by chemical exchange reactions of related $\mathrm{Tl}$ species, that is, redox reaction between $\mathrm{Tl}(\mathrm{I})$ and $\mathrm{Tl}(\mathrm{III})$ and ligand exchange reactions of them. The $\mathrm{Tl}$ isotope fractionation in the chemical exchange reactions is of interest, since it may result in the isotopic variation of $\mathrm{Tl}$ in nature.

The classic theory of isotope effect has been established by Urey, Bigeleisen, and Mayer [2,3]. The theory originates from the difference in the intramolecular vibrational energies of isotopologues. The theory predicts the mass-dependent isotope fractionation. The magnitude of isotope effect (isotope enrichment factor, $\varepsilon$ ) is proportional to $\delta m / m m$, where $\delta m$ means the isotopic mass difference of masses $m$ and $m$ ' of two isotopes (prime represents the light isotope). The vibrational isotope effect is predominant in isotope fractionation of light elements. The isotope effect found in heavy elements has frequently been larger than that expected by the classic theory. This is now recognized as the nuclear field shift effect [4,5]. The nuclear field shift effect, which results from the isotopic change in the nuclear size and shape, is larger for heavy elements and it is recognized as the major origin of the mass-independent isotope fractionation in chemical exchange reactions [4-11], for example, 1\%o/amu (atomic mass unit) fractionation is possible for $\mathrm{Hg}$ [6], Tl [6], Pb [7], and U [4,5,8-10]. For middle heavy elements, Mo [12], Ru [6,12], and Pd [13], 0.05-0.3\%/amu of the nuclear field shift effect is estimated. For light elements such as $\mathrm{Ni}$ [14] and $\mathrm{Zn}$ [15], the nuclear field shift effect is estimated to be small as $0.02-0.03 \%$ omu.

The nuclear field shift effect of $\mathrm{Tl}$ is demonstrated in the present study. The isotope fractionation in a two-phase distribution of $\mathrm{Tl}$ was studied, in which an aqueous solution and an organic solution were used. A macrocyclic compound called crown ether was selected as a complexation agent with $\mathrm{Tl}$. The isotopic ratio of $\mathrm{Tl}$, ${ }^{205} \mathrm{Tl}^{203} \mathrm{Tl}$, was measured precisely by multiple-collector inductively-coupled-plasma mass-spectrometry (MC-ICP-MS). As supporting information for the isotope separation factor obtained, we performed the molecular orbital calculations for related $\mathrm{Tl}$ complexes. The isotope fractionation via intramolecular vibrations was estimated as the reduced partition function ratio (RPFR) of isotopologues. The contribution of the nuclear volume to the RPFR was also estimated by ab initio methods.

66

\section{Experimental}


All chemicals were reagent grade. TlCl was dissolved in $\mathrm{HCl}$, and $0.1 \mathrm{~mol} \mathrm{dm}^{-3}(\mathrm{M}) \mathrm{Tl}(\mathrm{I})$ with various [HCl] was prepared. The natural potential of each aqueous phase was measured by using two-electrode system. A Pt wire and a $\mathrm{Ag} \mid \mathrm{AgCl}$ electrode were used as working and reference electrodes, respectively. The organic phase was $0.1 \mathrm{M}$ dicyclohexano-18-crown-6 (DC18C6) in 1,2-dichloroethane. A $7 \mathrm{~cm}^{3}$ aqueous solution and a $7 \mathrm{~cm}^{3}$ organic solution were mixed in a glass vial with a stirrer bar, and the glass vial was sealed. The two phases were stirred by a magnetic stirrer for $30 \mathrm{~min}$. After the extraction equilibrium was attained, the two phases were separated by centrifugation. An aliquot of the upper aqueous solution was taken for analysis. These procedures were carried out at $298 \pm 0.5 \mathrm{~K}$. The Tl concentration in the sample solution was analyzed by ICP-AES (Thermo Fisher Scientific, iCAP 6300 Duo).

Organic impurities carried over the extraction were separated from $\mathrm{Tl}$ on anion exchange resin (AG1X8 200-400 mesh) in $\mathrm{HBr} / \mathrm{HNO}_{3}$. The sample solution was dried up, and then dissolved into a few drops of 9M $\mathrm{HBr}$. This was dried up by heating once more, and then dissolved into $0.5 \mathrm{M} \mathrm{HBr}$ again. On the anion exchange resin in $0.5 \mathrm{M} \mathrm{HBr}$, Tl was strongly adsorbed while organic substances passed through freely. Finally, $\mathrm{Tl}$ was collected in $0.5 \mathrm{M} \mathrm{HNO}_{3}$. Since $\mathrm{Tl}$ was totally recovered, no isotope fractionation occurs in this procedure.

Solutions of purified $\mathrm{Tl}\left(40 \mathrm{ng} \mathrm{g}^{-1}\right.$ in $0.3 \mathrm{M} \mathrm{HNO}_{3}$ ) were analyzed on a Neptune (Thermo Fisher Scientific) MC-ICP mass spectrometer at the "Pole Spectrometrie Ocean" (PSO) of Brest. MC-ICP-MS technique has opened up high precision measurements of stable isotope ratios of heavy elements [16]. Samples and standards were spiked with Pb isotopic standard NIST981 (National Institute of Standards and Technology) to achieve $[\mathrm{Tl}] /[\mathrm{Pb}] \sim 4$ to correct for mass discrimination. Isotopes ${ }^{203} \mathrm{Tl},{ }^{205} \mathrm{Tl},{ }^{206} \mathrm{~Pb}$, and ${ }^{207} \mathrm{~Pb}$ were collected on Faraday cups and an exponential mass discrimination law [17] using ${ }^{207} \mathrm{~Pb} /{ }^{206} \mathrm{~Pb}=0.91464$ was applied to correct ${ }^{205} \mathrm{Tl} /{ }^{203} \mathrm{Tl}$ ratios. Procedural blanks and instrumental background were corrected simultaneously by measuring on peak zero signals. Analytical uncertainty was $0.04 \%(2 \sigma)$. No isobaric interference was observed. Each sample solution was analyzed 6 times by standard-sample bracketing.

The molecular geometries and vibrational frequencies of aqueous $\mathrm{Tl}(\mathrm{I})$ and $\mathrm{Tl}(\mathrm{III})$ species were calculated by using the density functional theory (DFT) implemented by the Gaussian03 code [18]. The DFT method employed here is a hybrid density functional consisting of Becke's [19] three-parameter non-local hybrid exchange potential (B3) with Lee-Yang-and Parr (LYP) [20] non-local functionals. The 6-31++G** basis set (all-electron basis set) was chosen for $\mathrm{H}, \mathrm{O}$, and $\mathrm{Cl}$. Stuttgart/Dresden effective core potential (SDD) compensated the relativistic effect [21] was chosen for Tl. 
The contribution of the nuclear volume was estimated by the numerical multiconfigurational

Dirac-Coulomb Hartree-Fock (MCDCHF) method implemented in the four-component relativistic atomic program package GRASP2K [22] and the Dirac-Coulomb Hartree-Fock (DCHF) method implemented in the UTChem program [23]. Calculations of the electronic structure of $\operatorname{Tl}^{0}\left([\mathrm{Xe}] 4 f^{14} 5 d^{10} 6 s^{2} 6 p^{1}\right), \mathrm{Tl}^{+}\left([\mathrm{Xe}] 4 f^{14} 5 d^{10} 6 s^{2}\right)$, $\mathrm{Tl}^{3+}\left([\mathrm{Xe}] 4 f^{14} 5 d^{10}\right)$, and a few simple $\mathrm{Tl}$ molecules were performed. Exponents of basis sets are taken from Faegri’s four-component basis for Tl [24], third-order Douglas-Kroll basis for $\mathrm{H}$ and $\mathrm{Cl}$ [25], and ANO-RCC for

104 O [26]. Contraction coefficients are optimized by four-component atomic calculations [27]. After we added some diffuse and polarization functions, the final contraction form of the large component basis sets is [23s21p14d9f]/(8s7p5d3f) for Tl, (16s11p1d)/[4s3p1d] for Cl, (14s9p2d)/[3s2p2d] for O, and (8s2p)/[3s2p] for $\mathrm{H}$.

More details are in the literature [8-10].

108

\section{Results and Discussion}

Chemical species of $\mathrm{Tl}(\mathrm{I})$ and $\mathrm{Tl}(\mathrm{III})$ in $\mathrm{HCl}$ media considered here are related through the following reactions,

$$
\mathrm{Tl}^{+}+n \mathrm{Cl}^{-} \rightleftarrows \mathrm{TlCl}_{n}{ }^{1-n}(n=1,2 \text {, or } 4)
$$

$$
\mathrm{Tl}^{3+}+n \mathrm{Cl}^{-} \rightleftarrows \mathrm{TlCl}_{n}^{3-n}(n=1,2,3 \text {, or } 4)
$$

$$
\mathrm{TlCl}_{n}{ }^{1-n} \rightleftarrows \mathrm{TlCl}_{n}{ }^{3-n}+2 \mathrm{e}^{-}
$$

where $n=3$ of reaction 1 was not found [28]. The stability constants of equilibria 1 and 2 have been reported in

116 literatures [28,29]. Complexation proceeds easily in the $\mathrm{HCl}$ system. According to the literature data [30] and the natural potentials measured, the aqueous phase prepared contains $0.2-0.5 \%$ of $\mathrm{Tl}(\mathrm{III})$, and the rests are $\mathrm{Tl}(\mathrm{I})$. Though the present system is mainly controlled by ligand exchange reactions of $\mathrm{Tl}(\mathrm{I})$, the redox reaction 3 exists. DC18C6 precedes ion association extraction, and hence the extraction reaction of $\mathrm{Tl}$ can be written as,

$$
\mathrm{Tl}^{+}+\mathrm{Cl}^{-}+\mathrm{L} \rightleftarrows \mathrm{TlLCl}
$$

$$
\mathrm{Tl}^{3+}+3 \mathrm{Cl}^{-}+\mathrm{L} \rightleftarrows \mathrm{TlLCl}_{3}
$$

where L stands for DC18C6. The distribution ratio is defined as,

$$
D=([\mathrm{Tl}(\mathrm{I})]+[\mathrm{Tl}(\mathrm{III})])_{\mathrm{org}} /([\mathrm{Tl}(\mathrm{I})]+[\mathrm{Tl}(\mathrm{III})])_{\mathrm{aq}}
$$

125 where subscripts org and $a q$ mean the organic and aqueous phases, respectively. Acidity dependence of $D$ 126 obtained is shown in Fig. 1a. High extractability of Tl(III) is known for HCl/DC18C6 systems [32]. Tl(I) is not extracted from diluted $\mathrm{HCl}$ but from concentrated $\mathrm{HCl}$ [32]. The steep increase of $D$ at low $[\mathrm{HCl}$ ] region is 
attributable to the extraction of Tl(III). The extraction of Tl(I) becomes significant with the increase of [HCl]. Anionic species of $\mathrm{Tl}$ chlorides form at concentrated $\mathrm{HCl}$ region, and this would depress the extraction of both $\mathrm{Tl}(\mathrm{I})$ and $\mathrm{Tl}(\mathrm{III})$. The extraction system is schematically shown in Fig 1b. The extraction behavior of $\mathrm{Tl}$ can be summarized as,

132 Low acidity: $\mathrm{Tl}(\mathrm{III})$ is mainly extracted to the organic phase. $\mathrm{Tl}(\mathrm{I})$ remains in the aqueous phase, which is partly oxidized to $\mathrm{Tl}(\mathrm{III})$.

134 High acidity: Both $\mathrm{Tl}(\mathrm{I})$ and $\mathrm{Tl}(\mathrm{III})$ are extracted to the organic phase. Higher complexation of $\mathrm{Tl}$ ions with $\mathrm{Cl}^{-}$ occurs in the concentrated $\mathrm{HCl}$.

$139\left(\left[{ }^{205} \mathrm{Tl}\right] /\left[{ }^{203} \mathrm{Tl}\right]\right)_{\text {ref. }}$ The $\delta^{205} \mathrm{Tl}$ values obtained are shown in Fig. 2. Analytical errors $(2 \sigma)$ of 6 replicates are shown

140 together. Small positive isotope fractionation was observed at high $[\mathrm{HCl}]$ region, while large negative isotope

141 fractionation at low $[\mathrm{HCl}]$ region.

142

Estimation of $T l$ isotope effect by ab initio methods

Firstly, we estimated the magnitude of the conventional mass effect. In order to evaluate the respective strength of mass-dependent effects, some quantum chemical calculations of the vibrational energies of the aqueous $\mathrm{Tl}(\mathrm{I})$ and $\mathrm{Tl}(\mathrm{III})$ species were performed. Coordination number of hydrated $\mathrm{Tl}$ species was set to 4-6 according to the literatures [33-36]. frequencies of these species were calculated in order to evaluate $\delta^{205} \mathrm{Tl}$. The isotope enrichment factor due to the intramolecular vibrations can be evaluated from the reduced partition function ratio (RPFR) [3], (s/s')f,

$$
\ln \left(s / s^{\prime}\right) f=\Sigma\left[\ln b\left(u_{\mathrm{i}}{ }^{\prime}\right)-\ln b\left(u_{\mathrm{i}}\right)\right]
$$

$$
\ln b\left(u_{\mathrm{i}}\right)=-\ln u_{\mathrm{i}}+u_{\mathrm{i}} / 2+\ln \left(1-\mathrm{e}^{-u \mathrm{i}}\right)
$$
variables referring to the light isotopologue. The isotope enrichment factor due to the molecular vibration can be evaluated from the frequencies ( $v$ ) summed over all the different modes. The RPFRs obtained for the isotope pair ${ }^{203} \mathrm{Tl}^{205} \mathrm{Tl}$ at $298 \mathrm{~K}$ are shown in Table 1 . The reported RPFRs calculated for hydrated $\mathrm{Tl}^{+}$and $\mathrm{Tl}^{3+}$ at $298 \mathrm{~K}[6]$ 
are shown together. Our calculations show quite good agreement with the reported values. Though the structure of the Tl-crown complex is not clear, a similar magnitude of the RPFR may be expected.

The acidity dependence of $\delta^{205} \mathrm{Tl}$ shown in Fig. 2 results from ligand exchange and/or redox reactions of $\mathrm{Tl}(\mathrm{I})$ and $\mathrm{Tl}(\mathrm{III})$ species. The RPFRs of $\mathrm{Tl}(\mathrm{I})$ are ranged in $0.02-0.08 \%$. The difference is only $0.06 \%$. The RPFRs of $\mathrm{Tl}(\mathrm{III})$ are ranged in $0.37-0.44 \%$. The difference is also $0.07 \%$. These values due to ligand exchange reactions are too small to distinguish as the isotope fractionation. The maximum difference in RPFRs between $\mathrm{Tl}(\mathrm{I})$ and $\mathrm{Tl}(\mathrm{III})$ species is $0.42 \%$. This magnitude due to redox reaction is 10 times smaller than $\delta^{205} \mathrm{Tl}$ found in low $[\mathrm{HCl}]$ region. The results indicate that the conventional mass effect is not the major origin of $\mathrm{Tl}$ isotope fractionation in our experimental system.

The nuclear field shift is an isotope shift in orbital electrons [37]. This results from the isotopic difference in the nuclear size and shape. For example, the root-mean-square charge radii $\left\langle r^{2}\right\rangle^{1 / 2}$ of ${ }^{203} \mathrm{Tl}$ and ${ }^{205} \mathrm{Tl}$ are $5.4664 \times 10^{-15} \mathrm{~m}$ and $5.4763 \times 10^{-15} \mathrm{~m}$ [38], respectively. The nuclear charge distribution gives an electric field, and its isotopic difference shifts the atomic energy levels, also displacing the electronic molecular states. The nuclear field shift effect $\ln K_{\mathrm{fs}}$ can be written.

$$
\ln K_{\mathrm{fs}}=h c v_{\mathrm{fs}} / k T
$$

where $v_{\mathrm{fs}}$ means nuclear field shift, and $h c v_{\mathrm{fs}}$ is the isotopic displacement of electronic energy level $\delta E$ due to the nuclear filed shift. In the present study, the total electronic energies at the ground states of $\mathrm{Tl}^{0}, \mathrm{Tl}^{+}$, and $\mathrm{Tl}^{3+}$ were calculated for different isotopes with different nuclear charge radii. Calculations for a few simple $\mathrm{Tl}$ molecules were also tested. The molecular structures were optimized by the similar method to obtain RPFRs.

The $\ln K_{\mathrm{fs}}$ values calculated are shown in Table 2 . The reference is $\mathrm{Tl}^{0} . \ln K_{\mathrm{fs}}$ values calculated by another DCHF method [6] are shown together. Our calculations agreed with the reported data. The nuclear field shift effect is attributable to the probability density of electrons at nucleus, and hence, drastic change in the electron configuration should cause a larger effect. A drastic case here is the $\mathrm{Tl}^{+}-\mathrm{Tl}^{3+}$ redox reaction. The difference of $\ln K_{\mathrm{fs}}$ values between $\mathrm{Tl}^{+}$and $\mathrm{Tl}^{3+}$ is $2.8 \%$. At low [HCl] region, $\mathrm{Tl}(\mathrm{III})$ is extracted in the organic phase and the major valence of $\mathrm{Tl}$ species in the aqueous phase is $\mathrm{Tl}(\mathrm{I})$. Since we measured the isotope fractionation in the aqueous phase, the isotope effect close to $-2.8 \%$ would be observed as $\delta^{205} \mathrm{Tl}$. The conventional mass effect as mentioned above is expected to be $\sim 0.42 \%$ of $\mathrm{The}^{+} \mathrm{Tl}^{+}-\mathrm{Tl}^{3+}$ redox reaction. Totally $\delta^{205} \mathrm{Tl}$ of $-3.2 \%$ is expected. Hence, the isotope fractionation of -3 to $-4 \%$ at low [HCl] region is possible by the isotope effect in the $\mathrm{Tl}^{+}-\mathrm{Tl}^{3+}$ redox reaction. With the increase of [HCl], $\mathrm{Tl}(\mathrm{I})$ is extracted and this would have depressed $\delta^{205} \mathrm{Tl}$. The ion association of $\mathrm{Tl}$ with $\mathrm{Cl}^{-}$would have changed ln $K_{\mathrm{fs}}$. It should be noted that the 
188 complexation of Tl with DC18C6 also creates the nuclear field shift effect during the extraction. The $\ln K_{\mathrm{fs}}$

189 values of hydration $\left(\mathrm{H}_{2} \mathrm{O}\right)$ and covalent bonding $\left(\mathrm{O}^{2-}\right)$ are shown in Table 2. Dehydration and complexation with

190 DC18C6 occur in the Tl extraction. If the coordination property of O donors of DC18C6 is similar to that of

191 hydrated water, the nuclear field shift effect in the DC18C6 complexation is insignificant due to the small

192 change in ln $K_{\mathrm{fs}}$. Conversely, the covalency of Tl-DC18C6 complex would result in a possible nuclear field shift

193 effect.

194

195 Conclusions

196 Thallium isotopes were fractionated in HCl/DC18C6 solvent extraction system. $\delta^{205} \mathrm{Tl}>1 \%$ was observed. The

197 conventional mass-dependent isotope fractionation estimated by the DFT calculation was smaller than the

198 experimental results. The nuclear field shift effect was estimated by the $a b$ initio method including a finite

199 nuclear model. The magnitude of nuclear field shift effect in the $\mathrm{Tl}^{+}-\mathrm{Tl}^{3+}$ redox reaction calculated was > 1\%o

200 and similar to $\delta^{205} \mathrm{Tl}$ experimentally obtained. Therefore, the nuclear field shift effect is most probable origin of

201 Tl isotope fractionation.

202

203 Acknowledgements

204 FM acknowledged the support of NASA COSMO \#NNX12AH70G, EXO \#NNX12AD88G, and ICARES

205 Washington University in St. Louis. AA thanks Conseil Régional de Bretagne for the funding of MS work. MA

206 thanks the Japan Society for the Promotion of Science for the funding of Grant-in-Aid for JSPS Fellows.

207

208 
210 [1] Deruck A, Dams R (1985) J Rarioanal Nucl Chem 94:87

211 [2] Urey HC (1947) J Chem Soc 562

212 [3] Bigeleisen J, Mayer MG (1947) J Chem Phys 15:261

213 [4] Bigeleisen J (1996) J Am Chem Soc 118:3676

214 [5] Nomura M, Higuchi N, Fujii Y (1996) J Am Chem Soc 118:9127

215 [6] Schauble EA (2007) Geochim Cosmochim Acta 71:2189

216 [7] Fujii T, Moynier F, Agranier A, Ponzevera E, Abe M (2011) Proc Radiochim Acta 1:387

217 [8] Abe M, Suzuki T, Fuji Y, Hada M (2008) J Chem Phys 128:144309.

218 [9] Abe M, Suzuki T, Fujii Y, Hada M, Hirao K (2008) J Chem Phys 129:164309

219 [10] Abe M, Suzuki T, Fujii Y, Hada M, Hirao K (2010) J Chem Phys 130:044309

220 [11] Fujii T, Moynier F, Albarède F (2009) Chem Geol 267:139

221 [12] Fujii T, Moynier F, Telouk P, Albarède F (2006) Astrophys J 647:1506

222 [13] Fujii T, Moynier F, Agranier A, Ponzevera E, Abe M (2011) Proc Radiochim Acta 1:339

223 [14] Fujii T, Moynier F, Dauphas N, Abe M (2011) Geochim Cosmochim Acta 75:469

224 [15] Fujii T, Moynier F, Telouk P, Abe M (2010) J Phys Chem 114:2543

225 [16] Zinner E, Moynier F, Stroud R (2011) Proc Natl Acad Sci 108:9135

226 [17] Maréchal C, Telouk P, Albarède F (1999) Chem Geol 156:251

227 [18] Frisch MJ, Trucks GW, Schlegel HB, Scuseria GE, Robb MA, Cheeseman JR, Montgomery Jr JA, Vreven 228 T, Kudin KN, Burant JC, Millam JM, Iyengar SS, Tomasi J, Barone V, Mennucci B, Cossi M, Scalmani G, Rega 229 N, Petersson GA, Nakatsuji H, Hada M, Ehara M, Toyota K, Fukuda R, Hasegawa J, Ishida M, Nakajima T, 230 Honda Y, Kitao O, Nakai H, Klene M, Li X, Knox JE, Hratchian HP, Cross JB, Adamo C, Jaramillo J, Gomperts 231 R, Stratmann RE, Yazyev O, Austin AJ, Cammi R, Pomelli C, Ochterski JW, Ayala PY, Morokuma K, Voth GA, 232 Salvador P, Dannenberg JJ, Zakrzewski VG, Dapprich S, Daniels AD, Strain MC, Farkas O, Malick DK, Rabuck 233 AD, Raghavachari K, Foresman JB, Ortiz JV, Cui Q, Baboul AG, Clifford S, Cioslowski J, Stefanov BB, Liu G, 234 Liashenko A, Piskorz P, Komaromi I, Martin RL, Fox DJ, Keith T, Al-Laham MA, Peng CY, Nanayakkara A, 235 Challacombe M, Gill PMW, Johnson B, Chen W, Wong MW, Gonzalez C, Pople JA Gaussian 03, Revision 6.1, 236 Gaussian, Inc., Pittsburgh PA, 2003

237 [19] Becke AD (1993) J Chem Phys 98:5648

238 [20] Lee CT, Yang WT, Parr RG (1988) Phys Rev B 37:785 
239 [21] Küchle W, Dolg WM, Stoll H, Preuss H (1991) Mol Phys 74:1245

240 [22] Jönsson P, He X, Fischer CF, Grant IP (2007) Comput Phys Commun 177:597

241 [23] The UTChem program package is available at http://utchem.qcl.t.u-tokyo.ac.jp/

242 [24] Faegri K (2001) Theo Chem Acc 105:252

243 [25] Tsuchiya T, Abe M, Nakajima T, Hirao K (2001) J Chem Phys 115:4463

244 [26] Roos BO, Lindh R, Malmqvist PÅ, Veryazov V, Widmark PO (2005) J Phys Chem A 109:6575

245 [27] Koc K, Ishikawa Y (1994) Phys Rev A 49:794

246 [28] Read AJ, Aldridge LP (1992) J Solution Chem 21:1231

247 [29] Woods MJM, Gallagher PK, Hugus ZZ, King EL (1964) Inorg Chem 3:1313

248 [30] Hughes RH, Garner CS (1942) J Am Chem Soc 64:1644

249 [31] Hardcastle JE, Jordan TA Alam I, Caswell LR (1984) J Radioanal Nucl Chem 87:259

250 [32] Koshima H, Onishi H (1986) Analyst 111:1261

251 [33] Lee HG (1972) Coord Chem Rev 8:289

252 [34] Blixt J, Glaser J, Mink J, Persson I, Persson P, Sandström M (1995) J Am Chem Soc 117:5089

253 [35] Persson I, Jaliehvand F, Sandström M (2002) Inorg Chem 41:192

254 [36] Vchirawangkwin V, Hoffer TS, Randolf BR, Rode BM (2007) J Comp Chem 28:1006

255 [37] King WH (1984) Isotope Shifts in Atomic Spectra, Plenum Press, New York

256 [38] Angeli I (2004) Atomic Data Nucl Data Tables 87:185

257

258 
Table 1. Logarithm of the reduced partition function, $\ln \left(\mathrm{s} / \mathrm{s}^{\prime}\right) f$, for isotope pair ${ }^{203} \mathrm{Tl}-{ }^{205} \mathrm{Tl}$ at $298 \mathrm{~K}$.

\begin{tabular}{lll}
\hline & & $10^{3} \ln \left(\mathrm{s} / \mathrm{s}^{\prime}\right) f$ \\
\hline $\mathrm{Tl}(\mathrm{I})$ & $\mathrm{Tl}\left(\mathrm{H}_{2} \mathrm{O}\right)_{6}{ }^{+}$ & $0.063\left(0.07^{\mathrm{a}}\right)$ \\
& $\mathrm{TlCl}\left(\mathrm{H}_{2} \mathrm{O}\right)_{5}$ & 0.078 \\
& $\mathrm{TlCl}_{2}\left(\mathrm{H}_{2} \mathrm{O}\right)_{4}{ }^{-}$ & 0.083 \\
& $\mathrm{TlCl}_{4}{ }^{3-}$ & 0.019 \\
\hline $\mathrm{Tl}(\mathrm{III})$ & $\mathrm{Tl}_{2} \mathrm{H}_{2}{ }_{6}{ }^{3+}$ & $0.423\left(0.65^{\mathrm{a}}\right)$ \\
& $\left.\mathrm{TlCl} \mathrm{H}_{2} \mathrm{O}\right)_{5}{ }^{2+}$ & 0.424 \\
& $\mathrm{TlCl}_{2}\left(\mathrm{H}_{2} \mathrm{O}\right)_{4}{ }^{+}$ & 0.444 \\
& $\mathrm{TlCl}_{3}\left(\mathrm{H}_{2} \mathrm{O}\right)_{2}$ & 0.400 \\
& $\mathrm{TlCl}_{4}{ }^{-}$ & 0.375 \\
\hline
\end{tabular}

270

${ }^{\mathrm{a}}$ Reference [6].

272

273 
Table 2. Nuclear field shift effect, ln $K_{\mathrm{fs}}$, for isotope pair ${ }^{203} \mathrm{Tl}-{ }^{205} \mathrm{Tl}$ at $298 \mathrm{~K}$.

\begin{tabular}{cllll}
\hline & & \multicolumn{3}{c}{$10^{3} \ln K_{\mathrm{fs}}{ }^{\mathrm{a}}$} \\
\cline { 3 - 5 } $\mathrm{Tl}(\mathrm{I})$ & $\mathrm{GRASP} 2 \mathrm{~K}$ & $\mathrm{UTChem}$ & DIRAC04 $^{\mathrm{b}}$ \\
& $\mathrm{Tl}^{+}$ & -0.221 & -0.157 & -0.22 \\
& $\mathrm{TlH}_{2} \mathrm{O}^{+}$ & & -0.168 & $-0.11^{\mathrm{c}}$ \\
& $\mathrm{TlCl}$ & & 0.004 & \\
\hline $\mathrm{Tl}(\mathrm{III})$ & $\mathrm{TlO}^{-}$ & & 0.283 & \\
& $\mathrm{Tl}^{3+}$ & 2.568 & 2.501 & 2.55 \\
& $\mathrm{TlH}_{2} \mathrm{O}^{3+}$ & & 1.898 & $1.97^{\mathrm{d}}$ \\
& $\mathrm{TlCl}^{2+}$ & & -0.677 & \\
& $\mathrm{TlO}^{+}$ & & -0.018 & \\
\hline
\end{tabular}

${ }^{\mathrm{a}}$ Nuclear field shift effect compared with $\mathrm{Tl}^{0}$ energy level.

286 b Reference [6].

$287{ }^{\mathrm{c}}$ Calculated for $\mathrm{Tl}\left(\mathrm{H}_{2} \mathrm{O}\right)_{3}{ }^{+}$

$288{ }^{\mathrm{d}}$ Calculated for $\mathrm{Tl}\left(\mathrm{H}_{2} \mathrm{O}\right)_{6}{ }^{3+}$

289

290 
292 Fig. 1 Distribution ratio and extraction scheme of Tl. (a) Distribution ratio of $\mathrm{Tl}$ as a function of [HCl]. (b)

293 Simplified schematic of Tl extraction

294 Fig. 2 Isotope fractionation of $\mathrm{Tl}$ as a function of [HCl]. Definition of $\delta^{205} \mathrm{Tl}$ is shown in Eq. 7. The $\delta^{205} \mathrm{Tl}$ values 295 with $2 \sigma$ analytical errors obtained are, $-4.14 \pm 0.28 \%$ o (2 M HCl), $-4.27 \pm 0.17 \%$ o (3 M HCl), $0.59 \pm 0.26 \%$ ( $4 \mathrm{M}$ $296 \mathrm{HCl}), 0.55 \pm 0.20 \%$ ( $6 \mathrm{M} \mathrm{HCl})$, and $0.83 \pm 0.28 \%$ o (7 M HCl).

297

298

299

300

301

302

303 


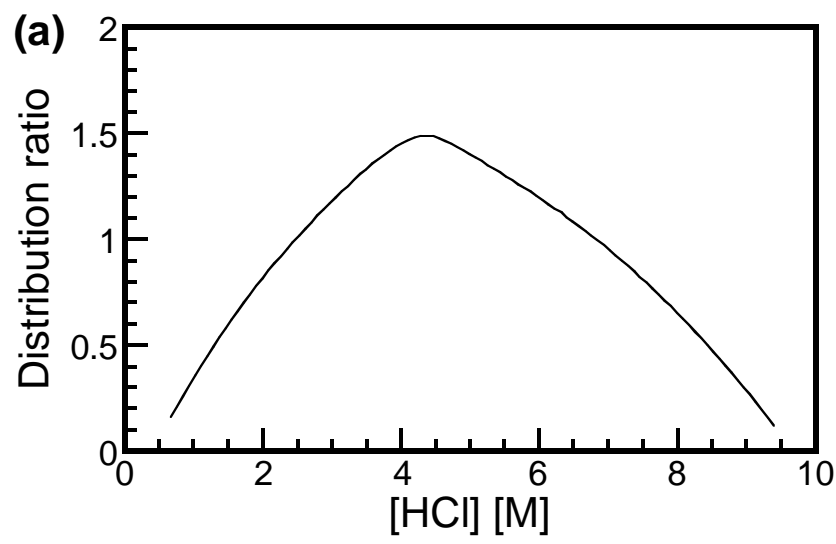

(b)

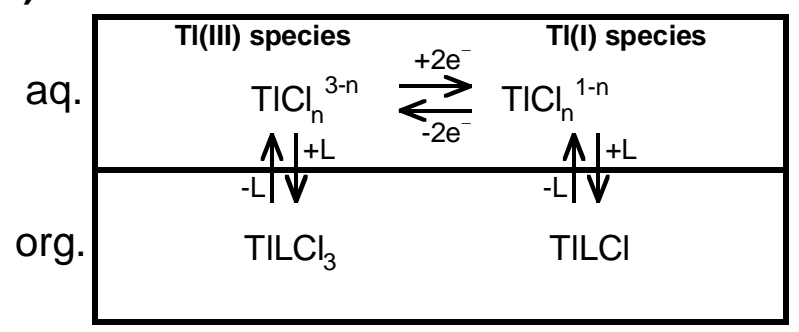

312

321 Figure 1 (Fujii et al.) 


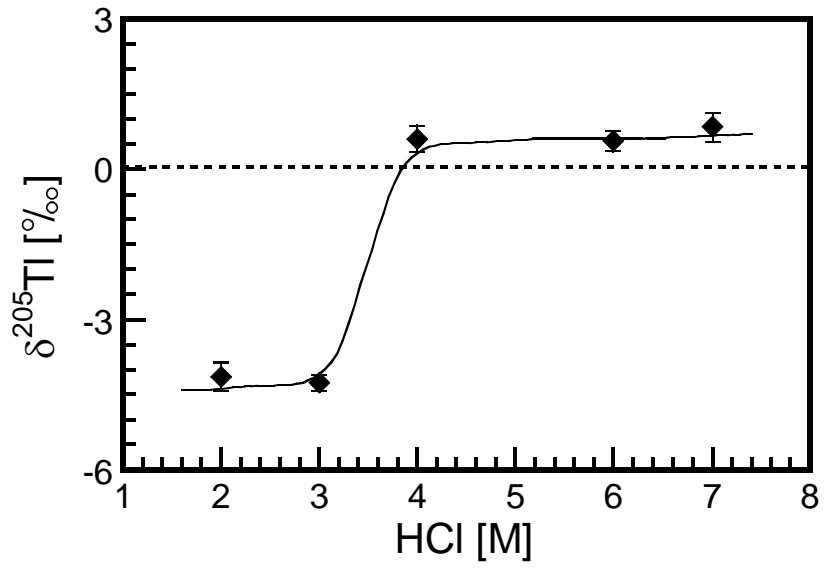

344 Figure 2 (Fujii et al.) 